\title{
Prosthetic Mesh Repair for Incarcerated Inguinal Hernia
}

\author{
Cihad Tatar ${ }^{1}$, İshak Sefa Tüzün², Tamer Karşıdağ ${ }^{3}$, Mehmet Celal Kızılkaya ${ }^{4}$, Erdem Yılmaz ${ }^{5}$
}

\author{
${ }^{1}$ Department of General Surgery, Besni State Hospital, Adiyaman, Turkey \\ ${ }^{2}$ Department of General Surgery, Haseki Training and Research Hospital, İstanbul, Turkey \\ ${ }^{3}$ Department of General Surgery, Ataşehir Memorial Hospital, İstanbul, Turkey \\ ${ }^{4}$ Department of General Surgery, Bulanık State Hospital, Muş, Turkey \\ ${ }^{5}$ Department of General Surgery, Çekirge State Hospital, Bursa, Turkey
}

Background: Incarcerated inguinal hernia is a commonly encountered urgent surgical condition, and tension-free repair is a well-established method for the treatment of noncomplicated cases. However, due to the risk of prosthetic material-related infections, the use of mesh in the repair of strangulated or incarcerated hernia has often been subject to debate. Recent studies have demonstrated that biomaterials represent suitable materials for performing urgent hernia repair. Certain studies recommend mesh repair only for cases where no bowel resection is required; other studies, however, recommend mesh repair for patients requiring bowel resection as well.

Aim: The aim of this study was to compare the outcomes of different surgical techniques performed for strangulated hernia, and to evaluate the effect of mesh use on postoperative complications.

Study Design: Retrospective cross-sectional study.

Methods: This retrospective study was performed with 151 patients who had been admitted to our hospital's emergency department to undergo surgery for a diagnosis of incarcerated inguinal hernia. The patients were divided into two groups based on the applied surgical technique. Group 1 consisted of 112 patients treated with mesh-based repair techniques, while Group 2 consisted of 39 patients treated with tissue repair techniques. Patients in Group 1 were further divided into two sub-groups: one consisting of patients undergoing bowel resection (Group 3), and the other consisting of patients not undergoing bowel resection (Group 4).

Results: In Group 1, it was observed that eight (7.14\%) of the patients had wound infections, while two $(1.78 \%)$ had hematomas, four $(3.57 \%)$ had seromas, and one $(0.89 \%)$ had relapse. In Group 2, one $(2.56 \%)$ of the patients had a wound infection, while three $(7.69 \%)$ had hematomas, one $(2.56 \%)$ had seroma, and none had relapses. There were no statistically significant differences between the two groups with respect to wound infection, seroma, hematoma, or relapse $(\mathrm{p}>0.05)$.

In Group 3, it was observed that one $(6.7 \%)$ of the patients had wound infections, while one $(6.7 \%)$ had a hematoma, one patient $(6.7 \%)$ had seroma, and none had relapses. In Group 4, seven (7.2\%) of the patients had wound infections, while one $(1 \%)$ had a hematoma, three $(3 \%)$ had seromas, and one $(1 \%)$ had a relapse. There were no significant differences between the two groups with respect to wound infection, seroma, hematoma, or relapse $(\mathrm{p}>0.05)$.

Conclusion: In urgent groin hernia repair surgeries, polypropylene mesh can be safely used even in the patients undergoing bowel resection.

Keywords: Incarcerated, inguinal hernia, prosthetic mesh
Inguinal hernia is a commonly encountered urgent condition in surgical clinics. An abdominal wall hernia is a protrusion of the abdominal tissues or organs through a weakness in the muscular structure of the wall of the abdomen. Inguinal and femoral hernias are usually classified together as groin hernias. It is believed that the prevalence of groin hernias in a population varies between $3 \%$ and $8 \%$. Between $75 \%$ and $85 \%$ of all hernias are observed in men. Inguinal hernias account for $80-83 \%$ of all hernias (59\% indirect inguinal hernias, $25 \%$ direct inguinal hernias, $5 \%$ femoral hernias). The most common hernias in both genders is inguinal hernia; however, femoral hernias are reported to be more common in women than in men (1-3).

This study was presented as an oral presentation at the $19^{\text {th }}$ National Surgical Congress, 16-20 April 2014, Antalya, Turkey.

Address for Correspondence: Dr. Cihad Tatar, Department of General Surgery, Besni State Hospital, Adiyaman, Turkey 
Incarcerated inguinal hernia is a commonly encountered urgent surgical condition, and tension-free repair is a wellestablished method for the treatment of non-complicated cases. However, due to the risk of prosthetic material-related infections, the use of mesh in the repair of strangulated or incarcerated hernia has often been the subject of debate. Recent studies have demonstrated that biomaterials represent suitable materials for performing urgent hernia repair. Certain studies recommend mesh repair only for cases where no bowel resection is required; other studies, however, recommend mesh repair for patients requiring bowel resection as well.

The aim of this study was to compare the outcomes of different surgical techniques performed for strangulated hernia, and to evaluate the effect of mesh use on postoperative complications.

\section{MATERIALS AND METHODS}

This retrospective study was performed with 151 patients who had been admitted to our hospital's emergency department between 2007 and 2013 to undergo surgery for a diagnosis of incarcerated inguinal hernia. Patients who died in the postoperative period due to systemic complications, as well as those who were lost during the follow-up period, were excluded from the study. The patients were divided into two groups based on the applied surgical technique. Group 1 consisted of 112 patients treated with mesh-based repair techniques, while Group 2 consisted of 39 patients treated with tissue repair techniques. The surgical technique to be applied was selected by the surgeons. The Lichtenstein procedure was used for inguinal hernia patients where mesh-based repair was preferred, while the Bassini procedure was used for inguinal hernia patients where the tissue repair technique was preferred. The mesh plug repair procedure was used for femoral hernia patients where the mesh repair was preferred, while the McVay procedure was used for femoral hernia patients where tissue repair was preferred. Patients in Group 1 were further divided into two sub-groups: one consisting of patients undergoing bowel resection (Group 3), and the other consisting of patients not undergoing bowel resection (Group 4). Thus, Group 3 antibiotherapy included patients who underwent mesh repair in addition to bowel resection, while Group 4 consisted of patients not assigned for bowel resection who underwent mesh repair.

All the patients were administered a single prophylactic dose of antibiotics; patients who underwent bowel resection received antibiotherapy for an additional two to four days.
Ethics committee approval was received for this study.

The Statistical Package for the Social Sciences (SPSS Inc.; Chicago, IL, USA) version 16.0 for Windows software package was used in data collection and statistical analysis.

The Chi-square test and Mann-Whitney $U$ test were used for statistical analysis. $\mathrm{P}$ values $<0.05$ were considered to be statistically significant.

\section{RESULTS}

Mesh-based repair techniques were performed on the 112 patients comprising Group 1, while tissue repair techniques were performed on the 39 patients comprising Group 2 (Table 1). In this study, $81.5 \%$ (23) of the patients were male, while $18.5 \%$ (28) were female. Female patients had a significantly higher ratio of femoral hernia than male patients, while male patients had a significantly higher ratio of inguinal hernia than female patients $(\mathrm{p}<0.05)$.

In Group 1, 83\% (93) of the patients were male, while $17 \%$ (19) were female. In Group 2, 77\% (30) of the patients were male, while $23 \%$ (9) were female. In Group 1, 87.5\% (98) of the patients had inguinal hernias, while $12.5 \%$ (14) had femoral hernias. In Group 2, 77\% (30) of the patients had inguinal hernias, while 23\% (9) had femoral hernias. In Group 1, 51.7\% (58) of the patients had hernias on the right side, while $48.3 \%$ (54) had hernias on the left side. In Group 2, 61.5\% (24) of the patients had hernias on the right side, and 38.5\% (15) had their hernias on the left side. There were no statistically significant differences between the two groups with respect to gender, hernia type, or hernia localization $(\mathrm{p}>0.05)$ (Table 2$)$.

In Group 1, it was observed that eight $(7.14 \%)$ of the patients had wound infections, while two $(1.78 \%)$ had hematomas, four $(3.57 \%)$ had seromas, and one $(0.89 \%)$ had a relapse. In Group 2, one $(2.56 \%)$ of the patients had a wound infection, while three $(7.69 \%)$ had hematomas, one $(2.56 \%)$ had seroma, and none had relapses. There were no statistically significant differences between the two groups with respect to the ratio of wound infection, seroma, hematoma, or relapse $(\mathrm{p}>0.05)$ (Table 3$)$.

\begin{tabular}{|c|c|c|}
\hline \multicolumn{3}{|c|}{ TABLE 1. Groups } \\
\hline \multicolumn{2}{|c|}{ Group 1 (Mesh-based repair) } & Group 2 (Tissue repair) \\
\hline \multicolumn{2}{|c|}{112} & \multirow{3}{*}{39} \\
\hline $\begin{array}{c}\text { Group 3 } \\
\text { (Mesh-based repair } \\
\text { with bowel resection) }\end{array}$ & $\begin{array}{c}\text { Group 4 } \\
\text { (Mesh-based repair } \\
\text { without bowel resection) }\end{array}$ & \\
\hline 15 & 97 & \\
\hline
\end{tabular}


TABLE 2. Gender, hernia type, and hernia localization for 151 patients who underwent surgical treatment for incarcerated hernias

\begin{tabular}{lccc}
\hline & $\begin{array}{c}\text { Group 1 } \\
(\text { Mesh-based repair }) \\
(\mathrm{n}=112)\end{array}$ & $\begin{array}{c}\text { Group 2 } \\
(\text { Tissue repair }) \\
(\mathrm{n}=39)\end{array}$ & $\mathrm{p}^{*}$ \\
\hline Male & $93(83 \%)$ & $30(77 \%)$ & 0.3976 \\
Female & $19(17 \%)$ & $9(23 \%)$ & \\
Inguinal & $98(87.5 \%)$ & $30(77 \%)$ & 0.1134 \\
Femoral & $14(12.5 \%)$ & $9(23 \%)$ & \\
Right & $58(51.7 \%)$ & $24(61.5 \%)$ & 0.2923 \\
Left & $54(48.3 \%)$ & $15(38.5 \%)$ & \\
*Chi-square test was used. & & \\
\hline
\end{tabular}

TABLE 3. Statistical analyses of complications for 151 patients who underwent surgical treatment for incarcerated hernias

\begin{tabular}{lccc}
\hline & $\begin{array}{c}\text { Group 1 } \\
(\text { Mesh-based repair }) \\
(\mathrm{n}=112)\end{array}$ & $\begin{array}{c}\text { Group 2 } \\
(\text { Tissue repair }) \\
(\mathrm{n}=39)\end{array}$ & $\mathrm{p}^{*}$ \\
\hline Wound infection & $8(7.14 \%)$ & $1(2.56 \%)$ & 0.3023 \\
Hematoma & $2(1.78 \%)$ & $3(7.69 \%)$ & 0.0780 \\
Seroma & $4(3.57 \%)$ & $1(2.56 \%)$ & 0.7681 \\
Relapse & $1(0.89 \%)$ & 0 & \\
*Mann-Whitney U-test was used. & &
\end{tabular}

It was determined that $8.92 \%$ (10) of the patients in Group 1 , and $20.51 \%$ (8) of the patients in Group 2 had comorbidities. In Group 1, the mean age of the patients was 53.54 years (range: 16-94 years), the mean hospitalization time was 2.27 days (range: 1-8 days), and the mean follow-up period was 37.3 months (range: 6-67 months). In Group 2, the mean age of the patients was 49.41 years (range: 9-85 years), the mean hospitalization time was 2.12 months (range: 1-17 months), and the mean follow-up period was 40.1 months (range: 2-62 months). There were no statistically significant differences between the two groups in terms of mean age, hospitalization time, and follow-up period ( $>0.05$ ) (Table 4).

In Group 3, 40\% (6) of the patients were male, while $60 \%$ (9) were female. In Group 4, 89.7\% (87) of the patients were male, while $10.3 \%$ (10) were female. In Group 1, 26.7\% (4) of the patients had inguinal hernias, while $73.3 \%$ (11) had femoral hernias. In Group 4, 89.7\% (87) of the patients had inguinal hernias, while $10.3 \%$ (10) had femoral hernias. The ratio of bowel resection requirement was significantly higher among female patients, as well as in patients with femoral hernias $(\mathrm{p}<0.05)$.

In Group 3, 40\% (6) of the patients had hernias on the right side and $60 \%$ (9) had hernias on the left side. In Group 4, $53.6 \%$ (52) of the patients had their hernias on the right side, $46.4 \%$ (45) had hernias on the left side. There were no statistically significant differences between the two groups in terms of hernia localization $(\mathrm{p}>0.05)$ (Table 5).
TABLE 4. Comorbidities, mean age, hospitalization time and follow-up period for 151 patients who underwent surgical treatment for incarcerated hernias

\begin{tabular}{lccc}
\hline & $\begin{array}{c}\text { Group 1 } \\
(\text { Mesh-based repair }) \\
(\mathrm{n}=112)\end{array}$ & $\begin{array}{c}\text { Group 2 } \\
(\text { Tissue repair })\end{array}$ & \\
& $10(8.92 \%)$ & $8(20.51 \%)$ & 0.0558 \\
Comorbidities & $53.54(16-94)$ & $49.41(9-85)$ & \\
Mean age & $(\mathrm{SD}: 19.01)$ & $(\mathrm{SD}: 21.63)$ & 0.3640 \\
Hospitalization time & $2.27(1-8)$ & $2.12(1-17)$ & \\
& $(\mathrm{SD}: 1.85)$ & $(\mathrm{SD}: 2.78)$ & 0.2344 \\
Follow-up period & $37.30(6-67)$ & $40.10(2-62)$ & \\
& $(\mathrm{SD}: 16.34)$ & $(\mathrm{SD}: 16.20)$ & 0.3176 \\
\hline
\end{tabular}

*Mann-Whitney U-test was used.

TABLE 5. Gender, hernia type, and hernia localization for 112 patients who underwent surgical treatment with mesh-based repair

\begin{tabular}{lccc}
\hline & $\begin{array}{c}\text { Group 3 } \\
\text { (Mesh-based } \\
\text { repair with } \\
\text { bowel resection) } \\
(\mathrm{n}=15)\end{array}$ & $\begin{array}{c}\text { Group 4 } \\
\text { (Mesh-based } \\
\text { repair without } \\
\text { bowel resection) } \\
(\mathrm{n}=97)\end{array}$ & p* \\
\hline Male & $6(40 \%) 87(89.7 \%)$ & $8(20.51 \%)$ & $<0.0001$ \\
Female & $9(60 \%)$ & $10(10.3 \%)$ & \\
Inguinal & $4(26.7 \%)$ & $87(89.7 \%)$ & $<0.0001$ \\
Femoral & $11(73.3 \%)$ & $10(10.3 \%)$ & \\
Right & $6(40 \%)$ & $52(53.6 \%)$ & 0.3263 \\
Left & $9(60 \%)$ & $45(46.4 \%)$ & \\
\hline
\end{tabular}

*Chi-square test was used.

In Group 3, 6.7\% (1) of the patients had wound infections, while $6.7 \%$ (1) had hematomas, $6.7 \%$ (1) had seromas, and none had relapses. In Group 4, 7.2\% (7) of the patients had wound infections, while $1 \%$ (1) had hematomas, $3 \%$ (3) had seromas, and $1 \%$ (1) had relapses. There were no statistically significant differences between the two groups in terms of wound infection, seroma, hematoma, or relapse $(\mathrm{p}>0.05)$ (Table 6$)$.

In Group 3 and Group 4, 26\% (4) and 8.2\% (8) of the patients had comorbidities, respectively. In Group 3, the mean age of the patients was 62.6 years (range: $32-82$ years), the mean hospitalization time was 5.73 months (range: 5-7 months), and the mean follow-up period was 37.8 months (range: 6-67 months). In Group 4, the mean age of the patients was 52.1 years (range: 16-94 years), the mean hospitalization time was 1.7 months (range: 1-8 months), and the mean follow-up period was 33.7 months (range: 7-62 months). Patients belonging to Group 3 had significantly higher comorbidity rates, higher mean age, and longer hospitalization times $(\mathrm{p}<0.05)$. There were no statistically significant differences between the two groups in terms of the mean follow-up period ( $p>0.05$ ) (Table 7). 
TABLE 6. Statistical analyses of complications for 112 patients who underwent surgical treatment with mesh-based repair

\begin{tabular}{lccc}
\hline & $\begin{array}{c}\text { Group 3 } \\
\text { (Mesh-based } \\
\text { repair with } \\
\text { bowel resection) } \\
(\mathrm{n}=15)\end{array}$ & $\begin{array}{c}\text { Group 4 } \\
\text { (Mesh-based } \\
\text { repair without } \\
\text { bowel resection) } \\
(\mathrm{n}=97)\end{array}$ & $\mathrm{p}^{*}$ \\
\hline Wound infection & $1(6.7 \%)$ & $7(7.2 \%)$ & 0.9466 \\
Hematoma & $1(6.7 \%)$ & $1(1 \%)$ & 0.1315 \\
Seroma & $1(6.7 \%)$ & $3(3 \%)$ & 0.4979 \\
Relapse & 0 & $1(1 \%)$ & \\
*Mann-Whitney U-test was used & & \\
\hline
\end{tabular}

TABLE 7. Comorbidities, mean age, hospitalization time and follow-up period for 112 patients who underwent surgical treatment with mesh-based repair

\begin{tabular}{|c|c|c|c|}
\hline & $\begin{array}{c}\text { Group } 3 \\
\text { Mesh-based } \\
\text { repair with } \\
\text { bowel resection } \\
\quad(n=15)\end{array}$ & $\begin{array}{c}\text { Group } 4 \\
\text { Mesh-based } \\
\text { repair without } \\
\text { bowel resection } \\
\quad(\mathrm{n}=97)\end{array}$ & $\mathrm{p}^{*}$ \\
\hline Comorbidities & $4(26.6 \%)$ & $8(8.2 \%)$ & 0.0102 \\
\hline Mean age & $\begin{array}{c}62.67(32-82) \\
(\mathrm{SD}: 17.09)\end{array}$ & $\begin{array}{c}52.13(16-94) \\
\text { (SD: 18.98) }\end{array}$ & 0.0438 \\
\hline Hospitalization time & $\begin{array}{l}5.73(5-7) \\
(\mathrm{SD}: 0.70)\end{array}$ & $\begin{array}{l}1.78(1-8) \\
(\mathrm{SD}: 1.36)\end{array}$ & $<0.0001$ \\
\hline Follow-up period & $\begin{array}{l}37.86 \text { (6-67) } \\
\text { (SD: 16.24) }\end{array}$ & $\begin{array}{l}33.73(7-62) \\
(S D: 17.07)\end{array}$ & 0.4343 \\
\hline
\end{tabular}

\section{DISCUSSION}

Incarcerated inguinal hernia is one of the most common urgent surgical conditions. Ten percent of patients with inguinal hernia present with incarceration, and require urgent surgical procedures. For inguinal hernias, the risk of strangulation varies between $0.29 \%$ and $2.9 \%$ (4).

Nearly $15 \%$ of all inguinal hernia repairs are associated with relapses, and most of them occur following old surgical techniques that do not include a mesh-repair $(5,6)$.

Although modern inguinal hernioplasty techniques do not affect mortality rates following incarceration, they are highly effective in reducing the relapse rate (7).

\section{Mesh}

The most commonly used prosthetic materials in tensionfree mesh repair are polymers, polypropylene, and polyester. Polypropylene is the most preferred of these, since it is provides the best prosthesis leading to fibroblast activation. The pore size of the mesh is also important. With pore sizes larger than $75 \mu \mathrm{m}$, it is easier for macrophages to penetrate the tissue, which helps to minimize the risk of infection (8).

In the current study, large pore monofilament polypropylene prostheses were used.

\section{Wound infection-recurrence}

Although tension-free mesh repair is considered to be the gold standard surgical procedure in inguinal hernia repair under elective conditions, it is not recommended for strangulated hernia repair since it may increase the risk of wound infection. However, recent studies have reported that strangulation is no longer a contraindication for tension-free mesh repair (9-19).

However, other studies report mesh as a potential cause of wound infection, describing that it may be necessary to perform mesh removal to limit the risk of infection $(20,21)$.

Papaziogas et al. (4) conducted a study of 75 patients with incarcerated hernia who underwent surgery in their study, where 33 patients were assigned to the tension-free mesh repair group (Group A), while 42 patients underwent hernioplasty with the Bassini procedure (Group B); the outcomes in both group were then compared. Two patients in Group A and four patients in Group B had wound infections; however, no statistically significant difference was identified between the groups. In Group B, hospitalization time was significantly longer. The mean follow-up period was nine years. One patient in Group A and two patients in Group B experienced relapse. This study reported that the use of polypropylene mesh in strangulated hernias can be considered safe.

Wysocki et al. (15) previously performed a study of 77 patients who underwent the Lichtenstein procedure. In this study, two of the patients had seromas, while two patients had limited wound infections. The study reported that the use of monofilament polypropylene mesh implantation in strangulated hernias is safe, with a low risk of local infection risk.

A study by Elsebae et al. (22) included fifty-four patients with incarcerated hernia who underwent surgery. Twentyseven of these patients were assigned to the Lichtenstein procedure, while 27 patients underwent the Bassini procedure. Among the patients who underwent the Lichtenstein procedure, one had seroma, one had wound infection, and none had relapses. Among the patients who were assigned the Bassini procedure, three had wound infections, while three had relapses. There were no statistically significant differences between the groups in terms of complications.

In a study by Pans et al. (23), no statistically significant difference was identified between mesh-repair and non-mesh repair in terms of wound infection. It was also reported that none of the nine patients who underwent bowel resection as well as mesh-repair had wound infections. 
In the current study, only one patient exhibited relapse. In this case, the mesh was removed after the patient developed a wound-infection in the postoperative period, and the relapse occurred approximately one year later. There were no statistically significant differences between the groups with respect to hematoma, seroma, or relapse.

\section{Bowel resection}

In a retrospective study previously performed by Dahlstrand et al. (24) on 8208 patients in Sweden between 1992 and 2006, it was reported that femoral hernias were significantly more common among women than men. The study revealed that being female and having femoral hernias increased the risks of incarceration, bowel resection, complications, and mortality. In the same study, it was also reported that older age had a noticeable impact on bowel resection and mortality rates.

Certain studies report femoral hernia and delaying visits to physicians can increase the risk of bowel resection (25-27).

In 2010, Ge et al. (26) reported that femoral hernia was a risk factor for bowel resection.

The study by Azari et al. (28) compared patients above and below 80 years old diagnosed with strangulated hernia, and reported that elderly age played a role in morbidity and mortality.

In a similar study, Compagna et al. (29) compared inguinal hernia patients above and below 80 years of age, and also reported that elderly age played a role in mortality and morbidity. The current study revealed that femoral hernias are significantly more common among women than men, and that the requirement for bowel resection was significantly higher in female patients, as well as in patients with femoral hernias.

A number of studies have reported that performing bowel resection increases the complication rates in incarcerated inguinal hernias, while the type of mesh used is not directly associated with postoperative complications (16).

In this study, patients who underwent bowel resection had significantly higher comorbidity rates, higher mean age, and longer hospitalization times.

In a study performed by Sawayama et al. (30), 2 of the 10 patients who received mesh repair in addition to bowel resection developed wound infection afterwards; on the other hand, none of the 64 patients who received mesh-repair only, without being assigned to bowel resection, developed any wound infection. The current study revealed that as long as a wound is kept clean and contamination-free, the use of mesh does not constitute a contraindication, even for cases where bowel resection is performed.
Certain authors claim that even when bowel resection is performed, the use of polypropylene mesh for implantation does not increase the risk of wound infection in strangulated hernia repair $(23,31)$. The current study similarly reported no statistically significantly differences in terms of hematoma, seroma and relapse occurrence between patients who received mesh repair in addition to bowel resection, and patients who only had mesh repair. There were also no statistically significant differences between Group 3 and Group 4 with respect to the mean follow-up period.

\section{Antibiotherapy}

The administration of antibiotics for two to four days to patients with incarcerated inguinal hernia repair is reported to decrease the risk of wound infection associated with mesh implants (32).

Most surgeons prefer to use antibiotic prophylaxis to prevent infection (33-36).

Yerdel et al. (35) claimed that the use of prophylactic single dose intravenous antibiotic would reduce the risk of wound infection.

In the current study, all patients were administered a single prophylactic dose of antibiotic; additionally, patients assigned to bowel resection received additional antibiotherapy for two to four days.

The current study revealed that the use of polypropylene mesh in incarcerated inguinal hernia repair has no negative effect on wound infection or complications. Considering the fact that traditional tissue repair techniques can increase the risk of relapse, the current study results revealed that polypropylene mesh can be used safely in urgent groin hernia repair, even in cases where bowel resection is required.

Limitations of our study include the fact that the surgeries were performed by the same surgeon; the fact that the study was retrospective, and the lack of standardization between the groups. As this study is a clinical trial, there was only a weak correlation in parameters such as gender and age, while performing comparisons between different groups was inevitably necessary.

Ethics Committee Approval: Ethics committee approval was received for this study from the ethics committee of Haseki Training and Research Hospital.

Informed Consent: N/A.

Peer-review: Externally peer-reviewed. 
Author contributions: Concept - C.T., İ.S.T.; Design - C.T., İ.S.T., T.K.; Supervision - İ.S.T., T.K.; Resource - C.T., İ.S.T.; Materials C.T., M.C.K., E.Y.; Data Collection and/or Processing - C.T., M.C.K., E.Y.; Analysis and/or Interpretation - C.T., İ.S.T.; Literature Search C.T., M.C.K., E.Y.; Writing - C.T.; Critical Reviews - İ.S.T., T.K.

Conflict of Interest: No conflict of interest was declared by the authors.

Financial Disclosure: The authors declared that this study has received no financial support.

\section{REFERENCES}

1. Skandalakis LJ, GadaczTR, Mansberger AR, Mitchell WE, Colborn GL, Skandalakis JE, Çeviri: Dr. Ünal Değerli: Modern Herni Tamiri 2002;1:3-250.

2. Lichtenstein IL, Shore JM. Simplified repair of femoral and reccurent inguinal hernia by a "plug" Technigue. Arm J Surg 1974;128:439-56. [Crossref]

3. Velitchkov NG, Losanoff JE, Kiossev KT, Grigorov GI, Kirov GK, Losanoff CE. The Lichtenstein open tension-free inguinal hernia repair using a new prosthetic mesh-Bulgarian irresorbableampoxen. Int Surg 1996;81:205-9.

4. Papaziogas B, Lazaridis C, Makris J, Koutelidakis J, Patsas A, Grigoriou M, et al. Tension-free repair versus modified Bassini technique (Andrews technique) for strangulated inguinal hernia: a com-parative study. Hernia 2005;9:156-9. [Crossref]

5. Noszczyk W, Szmidt J. ChirurgiaOgo'lna. In W. Noszczyk, O chirurgiipolskiejkon'ca XX wieku. Warszawa FundacjaPolskiPrzegla، d Chirurgiczny 2001;52-69.

6. Haapaniemi S, Gunnarsson U, Nordin P, Nisson E. Reoperation after recurrent hernia repair. Ann Surg 2001;234:122-6. [Crossref]

7. Petersen S, Henke G, Freitag M, Faulhaber A, Ludwig K. Deep prosthesis infection in incisional hernia repair: predictive factors and clinical outcome. Eur J Surg 2001;167:453-7. [Crossref]

8. Amid PK. Classification of biomaterials and their related complications in abdominal wall hernia surgery. Hernia 1997;1:1521. [Crossref]

9. Pavlidis TE, Atmatzidis KS, Lazaridis CN, Papaziogas BT, Makris JG, Papaziogas TB. Comparison between mod-ern mesh and conventional non-mesh methods of inguinal hernia repair. Minerva Chir 2002;57:7-12.

10. Zieren J, Zieren HU, Jacobe CA, Wenger FA, Müller JM. Prospective randomized study comparing laparoscopic and open tension-free inguinal hernia repair with Shouldice's operation. Am J Surg 1998;175:330-3. [Crossref]

11. Catena F, La Donna M, Gagliardi S, Mingolla P, Avanzolini A, Pasgualini E, et al. Use of prosthetic mesh in complicated incisional hernias. Minerva Chir 2002;57:363-9.
12. Henry X, Randiamanantsoa V, Verhaeghe P, Stoppa R. Is there a reasonable role for prosthetic materials in the emer-gency treatment of hernias? Chirurgie 1994;120:123-8.

13. Mauch J, Helbling C, Schlumpf R. Incarcerated and strangulated hernias-surgical approach and management. Swiss Surg 2000;6:28-31. [Crossref]

14. Wysocki A, Pozniczek M, Krzywon J, Bolt L. Use of polypropylene prostheses for strangulated inguinal and inci-sional hernias. Hernia 2001;5:105-6. [Crossref]

15. Wysocki A, Kulawik J, Pozniczek M, Strzalka M. Is the Lichtenstein operation of strangulated groin hernia a safe procedure? World J Surg 2006;30:2065-70. [Crossref]

16. Bessa SS, Katri KM, Abdel-Salam WN, Abdel-Baki NA. Early results from the use of the Lichtenstein repair in the management of strangulated groin hernia. Hernia 2007;11:239-42. [Crossref]

17. Atila K, Guler S, Inal A, Sokmen S, Karademir S, Bora S. Prosthetic repair of acutely incarcerated groin hernias: a prospective clinical observational cohort study. Langenbecks Arch Surg 2010;395:563-8. [Crossref]

18. Nieuwenhuizen J, van RamshorstGH, Ten Brinke JG, de Wit T, Van der Harst E, Hop WC, et al. The use of mesh in acute hernia: frequency and outcome in 99 cases. Hernia 2011;15:297-300. [Crossref]

19. Pans A, Desaive C, Jacquet N. Use of a preperitoneal prosthesis for strangulated groin hernia. Br J Surg 1997;84:310-2. [Crossref]

20. Taylor SG, O'Dwier PJ. Chronic groin sepsis following tensionfree inguinal hernioplasty. Br J Surg 1999;86:562-5. [Crossref]

21. Gilbert AI, Felton L. Infection in inguinal hernia repair: considering biomaterials and antibiotics. Surg Gynecol Obstet 1993;177:126-30.

22. Elsebae M, Nasr M, Said M. Tension-free repair versus Bassini technique for strangulated inguinal hernia: A controlled randomized study. Int J Surg 2008;6:302-5. [Crossref]

23. Pans A, Desaive C, Jacquet N. Use of preperitoneal prosthesis for strangulated groin hernia. Br J Surg 1997;84:310-2. [Crossref]

24. Dahlstrand U, Wollert S, Nordin P, Sandblom G, Gunnarsson U. Emergency Femoral Hernia Repair: A Study Based on a National Register. Ann Surg 2009;249:672-6. [Crossref]

25. Alvarez JA, BaldonedoRF, Bear IG, Solis JA, Alvarez P, Jorge JI. Incarcerated groin hernias in adults: presentation and outcome. Hernia 2004;8:121-6. [Crossref]

26. Ge BJ, Huang Q, Liu LM, Bian HP, Fan YZ. Risk factors for bowel resection and outcome in patients with incarcerated groin hernias. Hernia 2010;14:259-64. [Crossref]

27. Kurt N, Oncel M, Ozkan Z, Bingul S. Risk and outcome of bowel resection in patients with incarcerated groin hernias: retrospective study. World J Surg 2003;27:741-3. [Crossref] 
28. Azari Y, Perry Z, Kirshtein B. Strangulated groin hernia in octogenarians. Hernia 2015;19:443-7. [Crossref]

29. Compagna R, Rossi R, Fappiano F. Bianco T, Accurso A, Danzi $\mathrm{M}$, et al. Emergency groin hernia repair: implications in elderly. BMC Surg 2013;13:29-32. [Crossref]

30. Sawayama H, Kanemitsu K, Okuma T, Inoue K, Yamamoto K, Baba H. Safety of polypropylene mesh for incarcerated groin and obturator hernias: a retrospective study of 110 patients. Hernia 2013;13:1058-65.

31. Pans A, Plumacker A, Legrand M, Mohdad F, Dubois J, Meurisse $\mathrm{M}$, et al. Surgical treatment of incarcerated inguino-crural hernia with interposition of a preperitoneal prosthesis. Acta Chir Belg 1991;91:223-6.

32. Gervino L, Cangioni G, Renzi F. A retrospective study on the efficacy of short-term perioperative prophylaxis in abdominal wall surgery for hernia repair in 1254 patients. J Chemother 2000;3:34-7.
33. Rios A, Rodriguea JM, Munitiz V,Alcaraz P, Perez FD, Parrilla P. Antibiotic prophy-laxis in incisional hernia repair using prosthesis. Hernia 2001;5:148-52. [Crossref]

34. Celdran A, Frieyo O, de la PintaJC,SoutoJL, Esteban J, Rubio $\mathrm{JM}$, et al. The role of anti-biotic prophylaxis on wound infection after mesh hernia repair under local anesthesia on an ambulatory basis. Hernia 2004;8:20-2. [Crossref]

35. Yerdel MA, Akin EB, Dolalan S, Turkcapar AG, Pehlivan M, Gecim IE, et al. Effect of single-dose prophylactic ampicillin and sulbactam on wound infection after tension-free inguinal hernia repair with polypropylene mesh: the randomized, doubleblind, prospective trial. Ann Surg 2001;233:26-33. [Crossref]

36. Pikoulis E, Daskalakis P, Psallidas N, Karavokyros I, Stathoulopolos A, Godevenos D, et al. Marlex mesh prefix plug hernioplasty retrospective analysis of 856 operations. World J Surg 2005;29:231-4. [Crossref] 